\title{
Antifungal activity of the essential oil of Thymus pulegioides on Candida, Aspergillus and dermatophyte species
}

Correspondence

Eugénia Pinto epinto@ff.up.pt

Received 30 November 2005 Accepted 15 June 2006
Eugénia Pinto, ${ }^{1}$ Cidália Pina-Vaz, ${ }^{2,3}$ Lígia Salgueiro, ${ }^{4}$ Maria José Gonçalves, ${ }^{4}$ Sofia Costa-de-Oliveira, ${ }^{2}$ Carlos Cavaleiro, ${ }^{4}$ Ana Palmeira, ${ }^{1}$ Acácio Rodrigues ${ }^{2,3}$ and José Martinez-de-Oliveira ${ }^{5}$

\author{
${ }^{1}$ Department of Microbiology/CEQOFF, Faculty of Pharmacy, University of Porto, 4050-Porto, \\ Portugal \\ ${ }^{2}$ Department of Microbiology, Faculty of Medicine, University of Porto, 4200-Porto, Portugal \\ ${ }^{3}$ IPATIMUP - Institute of Pathology and Molecular Immunology, University of Porto, \\ 4200-Porto, Portugal \\ ${ }^{4}$ Department of Pharmacognosy, Faculty of Pharmacy/CEF, University of Coimbra, \\ 3000-Coimbra, Portugal \\ ${ }^{5}$ Department of Obstetrics/Gynaecology, Faculty of Medicine, University of Beira-Interior, \\ 6200-Covilhã, Portugal
}

The composition of the essential oil of Thymus pulegioides and its antifungal activity on Candida, Aspergillus and dermatophyte fungal strains were studied. Essential oil from the aerial parts of the plant was obtained by hydrodistillation and analysed by GC and GC-MS. The oil showed high contents of carvacrol and thymol. The MIC and minimal lethal concentration were used to evaluate the antifungal activity against Candida (seven clinical isolates and four ATCC type strains), Aspergillus [five clinical isolates, and two Colección Española de Cultivos Tipo (CECT) and two ATCC type strains] and five clinical dermatophyte strains. Antifungal activity was evaluated for the essential oil and for its main components. To clarify its mechanism of action on yeasts and filamentous fungi, flow-cytometric studies of cytoplasmic membrane integrity were performed, and the effect on the amount of ergosterol was investigated. Results showed that T. pulegioides essential oil exhibited a significant activity against clinically relevant fungi, mainly due to lesion formation in the cytoplasmic membrane and a considerable reduction of the ergosterol content. The present study indicates that $T$. pulegioides essential oil has considerable antifungal activity, deserving further investigation for clinical applications.

\section{INTRODUCTION}

Fungal infections have been increasing in recent years due to a growing number of high-risk patients, particularly immunocompromised hosts. Candida is the third- or fourth-most-common isolate in nosocomial bloodstream infections in the USA. In addition, candidosis is the most common invasive fungal infection in critically ill nonneutropenic patients (Eggimann et al., 2003). The mortality rate due to invasive aspergillosis increased by $357 \%$ between 1980 and 1997 in the USA (McNeil et al., 2001). Dermatomycoses are common infections caused by members of the genus Candida and by filamentous fungi, particularly the dermatophytes. Superficial candidosis and dermatophytosis can be severe in immunocompromised patients.

Abbreviations: MLC, minimal lethal concentration; PI, propidium iodide.
In spite of the introduction of new antifungal drugs, they are limited in number. The increase of fungal resistance to classical drugs, the treatment costs, and the fact that most available antifungal drugs have only fungistatic activity, justify the search for new strategies (Rapp, 2004).

Aromatic plants have been widely used in folk medicine. It is known that most of their properties are due to their volatile oils. Essential oils from many plants are known to possess antifungal activity (Kalemba \& Kunicka, 2003), but only limited information exists about activity toward human fungal pathogens. They have been empirically used as antimicrobial agents, but the mechanisms of action are still unknown.

According to our preliminary results (Pina-Vaz et al., 2004; Salgueiro et al., 2003, 2004), some essential oils show an 
important antifungal activity against yeasts, dermatophyte fungi and Aspergillus strains, which could predict therapeutic benefits, mainly for diseases with mucosal, cutaneous and respiratory tract involvement.

Several studies have shown that thyme oils, particularly those of Thymus vulgaris and Thymus zygis (Bruneton, 1999; Pina-Vaz et al., 2004; Stahl-Biskup \& Sáez, 2002), possess antimicrobial activity, those of the phenol type being the most active. The limited occurrence of these phenols in nature is one of the reasons why Thymus oils containing thymol and carvacrol have been of great interest for some time.

Thymus pulegioides is widely distributed on the European continent south of the Mediterranean isles. In Portugal, it grows in the northeast, and it is locally used as an antiseptic. Previous results have demonstrated that this species is polymorphic (Salgueiro, 1994; Stahl-Biskup \& Sáez, 2002), and that the thymol/carvacrol chemotype is one of the most abundant in Portugal.

The objective of our present research was to evaluate the antifungal activity and investigate the mechanism of action of this specific chemotype and of its main components.

\section{METHODS}

Fungal organisms. The antifungal activity of the essential oil and its main components was evaluated against Candida, Aspergillus and dermatophyte strains: seven clinical Candida strains, two of Candida albicans (M1, H37), one of Candida krusei (H9), one of Candida tropicalis (H18), one of Candida guillermondii (Mat23) and two of Candida glabrata (H16, H30) isolated from recurrent cases of vulvovaginal candidosis, and four ATCC type strains (C. albicans ATCC 10231, C. tropicalis ATCC 13803, Candida parapsilosis ATCC 90018 and C. krusei ATCC 6258); five Aspergillus clinical strains, one of Aspergillus niger (F01), three of Aspergillus fumigatus (F05, F07 and F17) and one of Aspergillus flavus (F44) isolated from bronchial secretions, as well as two ATCC type strains (A. niger ATCC 16404 and A. fumigatus ATCC 46645) and two CECT type strains (A. niger CECT 2574 and A. fumigatus CECT 2071); and five dermatophyte clinical strains (Microsporum canis FF1, Microsporum gypseum FF3, Trichophyton rubrum FF5, Trichophyton mentagrophytes FF7 and Epidermophyton floccosum FF9) isolated from nails and skin.

C. parapsilosis ATCC 90018 and C. krusei ATCC 6258 were used as controls. The fungal isolates were identified by standard microbiology methods and stored in Sabouraud dextrose broth with glycerol at $-70{ }^{\circ} \mathrm{C}$.

Plant material and chemicals. Aerial parts of the plants were collected at the flowering stage from Moimenta, Trás-os-Montes (north of Portugal). A voucher specimen was deposited at the Herbarium of the Instituto Botânico of the University of Coimbra (COI).

Thymol (99.5\%) was purchased from DBH, and carvacrol, $\gamma$-terpinene and $p$-cymene (all $99 \cdot 5 \%$ ) from Fluka.

Essential oil analysis. Essential oil was isolated by water distillation for $3 \mathrm{~h}$ from air-dried material, using a Clevenger-type apparatus, according to the procedure described in the European Pharmacopoeia (Council of Europe, 1997).
Analysis of volatile oil was carried out by GC and GC-MS. Analytical GC was carried out in a Hewlett Packard 6890 gas chromatograph (Agilent Technologies) with a Hewlett Packard GC ChemStation Rev. A.05.04 data-handling system, equipped with a single injector and two flame-ionization detectors (FIDs). A graphpak divider (Agilent Technologies, part no. 5021-7148) was used for simultaneous sampling to two Supelco fused silica capillary columns with different stationary phases: SPB- 1 (polydimethylsiloxane, $30 \mathrm{~m} \times 0 \cdot 20 \mathrm{~mm}$ i.d., film thickness $0.20 \mu \mathrm{m}$ ) and SupelcoWax 10 (polyethyleneglycol, $30 \mathrm{~m} \times 0.20 \mathrm{~mm}$ i.d., film thickness $0 \cdot 20 \mu \mathrm{m})$. The oven temperature programme was $70-220^{\circ} \mathrm{C}\left(3{ }^{\circ} \mathrm{C} \mathrm{min}-1\right), 220^{\circ} \mathrm{C}(15 \mathrm{~min})$; the injector temperature was $250^{\circ} \mathrm{C}$; the carrier gas helium, adjusted to a linear velocity of $30 \mathrm{~cm} \mathrm{~s}^{-1}$; the splitting ratio 1:40; and the detector temperature $250{ }^{\circ} \mathrm{C}$.

GC-MS analyses were carried out in a Hewlett Packard 6890 gas chromatograph fitted with an HP1 fused silica column (polydimethylsiloxane, $30 \mathrm{~m} \times 0.25 \mathrm{~mm}$ i.d., film thickness $0 \cdot 25 \mu \mathrm{m})$, interfaced with a Hewlett Packard mass selective detector 5973 (Agilent Technologies) operated by Hewlett Packard Enhanced ChemStation software, version A.03.00. GC parameters were as above, and other parameters were as follows: interface temperature, $250^{\circ} \mathrm{C}$; MS source temperature, $230^{\circ} \mathrm{C}$; MS quadrupole temperature, $150{ }^{\circ} \mathrm{C}$; ionization energy, $70 \mathrm{eV}$; ionization current, $60 \mu \mathrm{A}$; scan range, 35-350 u; scans per second, $4 \cdot 51$.

The identity of the components was ascertained based on their retention indices, calculated by linear interpolation relative to retention times of a series of $n$-alkanes, and their mass spectra, which were compared with those from our own library and literature data (Adams, 1995; Joulain \& Konig, 1998). Relative amounts of individual components were calculated based on GC peak areas without FID response factor correction.

Antifungal activity. MICs, determined by the macrodilution broth method, and minimal lethal concentrations (MLCs) were performed according to reference documents M27-A and M38-A (National Committee for Clinical Laboratory Standards, 1997, 2002) for yeasts and filamentous fungi, respectively.

Serial twofold dilutions in DMSO, ranging from 0.02 to $20 \mu \mathrm{ml}^{-1}$, were tested for essential oil and its main components (thymol, carvacrol, $p$-cymene and $\gamma$-terpinene). In addition, the reference antifungal compounds, fluconazole (Pfizer) for yeasts and dermatophytes, or amphotericin B (Sigma) for Aspergillus, were used as standard antifungal drugs. Twofold serial dilutions ranging from $0 \cdot 25$ to $128 \mu \mathrm{g} \mathrm{ml}^{-1}$ for fluconazole and 0.016 to $16 \mu \mathrm{g} \mathrm{ml}^{-1}$ for amphotericin B were used.

Quality control determinations of the MICs of fluconazole and amphotericin B were performed by testing C. parapsilosis ATCC 90018 and C. krusei ATCC 6258. The results obtained were within the recommended limits.

These experiments performed in duplicate were repeated independently three times and yielded essentially the same results. A range of values is presented where different results were obtained. Two growth controls, RPMI medium and RPMI with $2 \cdot 0 \%(\mathrm{v} / \mathrm{v})$ DMSO, were included for each strain.

\section{Mechanism of activity}

Lesion of cytoplasmic membrane. Flow cytometry analysis using propidium iodide (PI; Sigma) was performed. PI is a fluorescent probe used to study the effect of drugs on membranes. It only penetrates cells with severe membrane lesions, showing increased red fluorescence (Pina-Vaz et al., 2001). Cells $\left(10^{6} \mathrm{ml}^{-1}\right)$ were incubated with serial concentrations of the oil and its main components 
Table 1. Constituents of the essential oil of T. pulegioides

T, Trace $(<0 \cdot 05 \%)$.

\begin{tabular}{|c|c|c|c|}
\hline Compound ${ }^{\star}$ & $\begin{array}{c}\text { RI } \\
\text { SPB-1 } \dagger\end{array}$ & $\begin{array}{c}\text { RI } \\
\text { SW } 10 \neq\end{array}$ & $\begin{array}{c}\text { Percentage } \\
\text { of total }\end{array}$ \\
\hline Tricyclene & 921 & 1029 & $0 \cdot 1$ \\
\hline$\alpha$-Thujene & 922 & 1029 & $0 \cdot 5$ \\
\hline$\alpha$-Pinene & 930 & 1030 & $1 \cdot 0$ \\
\hline Camphene & 943 & 1077 & $1 \cdot 5$ \\
\hline Oct-1-en-3-ol & 959 & 1447 & $2 \cdot 0$ \\
\hline Octan-3-one & 962 & - & $3 \cdot 9$ \\
\hline Sabinene & 964 & 1128 & $0 \cdot 2$ \\
\hline$\beta$-Pinene & 970 & 1118 & $0 \cdot 5$ \\
\hline Myrcene & 980 & 1161 & $1 \cdot 2$ \\
\hline$\alpha$-Phellandrene & 997 & 1171 & $0 \cdot 1$ \\
\hline$\Delta$-3-Carene & 1005 & 1152 & $\mathrm{~T}$ \\
\hline$\alpha$-Terpinene & 1010 & 1187 & $0 \cdot 9$ \\
\hline p-Cymene & 1011 & 1275 & $7 \cdot 8$ \\
\hline 1,8-Cineole & 1019 & 1214 & $1 \cdot 4$ \\
\hline Limonene & 1020 & 1206 & $0 \cdot 6$ \\
\hline$Z$ - $\beta$-Ocimene & 1025 & 1235 & $\mathrm{~T}$ \\
\hline$\gamma$-Terpinene & 1046 & 1249 & $8 \cdot 8$ \\
\hline trans-Sabinene hydrate & 1050 & 1459 & $1 \cdot 0$ \\
\hline$n$-Octanol & 1052 & - & $1 \cdot 1$ \\
\hline p-Cymene-8-ol & 1158 & 1845 & $0 \cdot 1$ \\
\hline$\alpha$-p-Dimethylstyrene & 1071 & - & $0 \cdot 1$ \\
\hline Terpinolene & 1076 & 1288 & $0 \cdot 2$ \\
\hline cis-Sabinene hydrate & 1080 & 1544 & $0 \cdot 4$ \\
\hline Linalool & 1082 & 1543 & $0 \cdot 6$ \\
\hline Camphor & 1118 & 1515 & $3 \cdot 9$ \\
\hline trans-Verbenol & 1125 & 1668 & $0 \cdot 1$ \\
\hline Borneol & 1144 & 1695 & $2 \cdot 9$ \\
\hline Terpinene-4-ol & 1158 & 1597 & $0 \cdot 2$ \\
\hline trans-Dihydrocarvone & 1167 & 1602 & $\mathrm{~T}$ \\
\hline$\alpha$-Terpineol & 1169 & 1692 & $0 \cdot 1$ \\
\hline Cuminaldehyde & 1211 & 1774 & $\mathrm{~T}$ \\
\hline Neral & 1214 & 1679 & $\mathrm{~T}$ \\
\hline Thymyl methyl ether & 1214 & 1583 & $0 \cdot 7$ \\
\hline Carvacryl methyl ether & 1223 & 1601 & $1 \cdot 0$ \\
\hline Geraniol & 1233 & 1842 & $0 \cdot 1$ \\
\hline Bornyl acetate & 1264 & 1574 & $0 \cdot 1$ \\
\hline Thymol & 1268 & 2183 & $26 \cdot 0$ \\
\hline Carvacrol & 1275 & 2212 & $21 \cdot 0$ \\
\hline$\alpha$-Cubebene & 1342 & 1455 & $0 \cdot 1$ \\
\hline Geranyl acetate & 1359 & 1755 & $\mathrm{~T}$ \\
\hline$\alpha$-Copaene & 1369 & 1487 & $\mathrm{~T}$ \\
\hline$\beta$-Bourbonene & 1376 & 1517 & $0 \cdot 3$ \\
\hline E-Caryophyllene & 1408 & 1590 & $1 \cdot 8$ \\
\hline$E$ - $\alpha$-Bergamotene & 1427 & 1580 & $\mathrm{~T}$ \\
\hline$\alpha$-Humulene & 1442 & 1665 & $0 \cdot 1$ \\
\hline$E$ - $\beta$-Farnesene & 1447 & 1666 & $0 \cdot 1$ \\
\hline allo-Aromadendrene & 1447 & 1636 & $\mathrm{~T}$ \\
\hline$\gamma$-Muurolene & 1464 & 1683 & $0 \cdot 2$ \\
\hline Germacrene-D & 1466 & 1699 & $1 \cdot 9$ \\
\hline$\beta$-Bisabolene & 1495 & 1723 & $3 \cdot 0$ \\
\hline$\gamma$-Cadinene & 1498 & 1751 & $\mathrm{~T}$ \\
\hline$\delta$-Cadinene & 1508 & 1751 & $0 \cdot 2$ \\
\hline
\end{tabular}

Table 1. cont.

\begin{tabular}{|lccc|}
\hline Compound $^{*}$ & $\begin{array}{c}\text { RI } \\
\text { SPB-1 } \dagger\end{array}$ & $\begin{array}{c}\text { RI } \\
\text { SW } \mathbf{1 0} \neq\end{array}$ & $\begin{array}{c}\text { Percentage } \\
\text { of total }\end{array}$ \\
\hline$\beta$-Sesquiphellandrene & 1510 & 1763 & $\mathrm{~T}$ \\
$\alpha$-Bisabolene & 1529 & 1767 & $0 \cdot 1$ \\
Spathulenol & 1553 & 2113 & $0 \cdot 1$ \\
Caryophyllene oxide & 1557 & 1968 & $0 \cdot 2$ \\
$\alpha$-Cadinol & 1628 & 2218 & $0 \cdot 1$ \\
Monoterpene hydrocarbons & - & - & $23 \cdot 5$ \\
Oxygen-containing monoterpenes & - & - & $59 \cdot 8$ \\
Sesquiterpene hydrocarbons & - & - & $7 \cdot 8$ \\
Oxygen-containing sesquiterpenes & - & - & $0 \cdot 4$ \\
Others & - & - & $7 \cdot 0$ \\
Total identified & - & - & $98 \cdot 5$ \\
\hline
\end{tabular}

${ }^{*}$ Compounds listed in order of elution from the Supelco SPB-1 column.

$\dagger \mathrm{RI}$ SPB- 1 signifies GC-retention indices relative to $\mathrm{C}_{9}-\mathrm{C}_{23} n$-alkanes on the SPB-1 column.

‡RI SW 10 signifies GC-retention indices relative to $C_{9}-C_{23} n$-alkanes on the Supelco Supelcowax-10 column.

$\left(0 \cdot 32-1 \cdot 25 \mu \mathrm{ml}^{-1}\right)$ for $1 \mathrm{~h}$ (Candida) or $7 \mathrm{~h}$ (Aspergillus), and then stained with $1 \mu \mathrm{g} \mathrm{PI} \mathrm{ml}{ }^{-1}$ for $30 \mathrm{~min}$. Cells were also incubated with the same compounds, at MLC values, for 5, 10, 15 and $30 \mathrm{~min}$ at $30{ }^{\circ} \mathrm{C}$ for $C$. albicans, representing yeasts, and $3,5,7$ and $16 \mathrm{~h}$ for A. fumigatus and A. niger, representing moulds. Scattergram analysis was performed to evaluate morphological changes (size and complexity). The percentage of stained cells at FL3 $(620 \mathrm{~nm}$, red), representing dead cells with severe lesions of the membrane, was quantified.

Study of ergosterol amount. For determination of the amount of ergosterol, the strains were incubated in RPMI medium (Sigma) supplemented with $2 \%$ glucose (Difco) for $48 \mathrm{~h}$ at $35^{\circ} \mathrm{C}$ (yeasts), 3 days at $25^{\circ} \mathrm{C}$ (Aspergillus) or 5 days at $25^{\circ} \mathrm{C}$ (dermatophytes), while shaking. A quantification of ergosterol amount was performed after incubation with and without the essential oil, its main components, or fluconazole as control, at both MIC and subinhibitory concentrations. Ergosterol was isolated from fungal cells by saponification, and the non-saponifiable lipids were extracted with heptane. Ergosterol was identified by its spectrophotometric absorbance profile (230-300 nm) (Arthington-Skaggs et al., 1999).

\section{RESULTS AND DISCUSSION}

The oil was obtained from air-dried plant material in a yield of $1.8 \%(\mathrm{v} / \mathrm{w})$. The qualitative and quantitative composition of the oil analysed is shown in Table 1. Fifty-seven components representing $98.5 \%$ of the volatile oil were identified. The oil was characterized by high amounts of thymol $(26.0 \%)$, and of carvacrol $(21 \cdot 0 \%)$ and its biogenetic precursors, $\gamma$-terpinene $(8 \cdot 8 \%)$ and $p$-cymene $(7 \cdot 8 \%)$ (thymol/carvacrol chemotype).

Evaluation of MIC and MLC showed that the oil was active against all the tested strains (Table 2). T. pulegioides essential oil exhibited significant antifungal activity. MIC values 
Table 2. Antimicrobial activity (MIC and MLC) of the essential oil of the thymol/carvacrol chemotype of T. pulegioides and its major compounds for Candida, dermatophyte and Aspergillus strains

Results were obtained from three independent experiments performed in duplicate. NT, Not tested.

\begin{tabular}{|c|c|c|c|c|c|c|c|c|c|c|c|c|c|c|}
\hline \multirow[t]{2}{*}{ Strains } & \multicolumn{2}{|c|}{ Essential oil } & \multicolumn{2}{|c|}{ Thymol } & \multicolumn{2}{|c|}{ Carvacrol } & \multicolumn{2}{|c|}{$p$-Cymene } & \multicolumn{2}{|c|}{$\gamma$-Terpinene } & \multicolumn{2}{|c|}{ Fluconazole } & \multicolumn{2}{|c|}{ Amphotericin B } \\
\hline & $\mathrm{MIC}^{\star}$ & MLC $^{\star}$ & $\mathrm{MIC}^{\star}$ & $\mathrm{MLC}^{*}$ & MIC $^{\star}$ & MLC $^{\star}$ & $\mathrm{MIC}^{*}$ & MLC $^{*}$ & $\mathrm{MIC}^{*}$ & MLC $^{*}$ & $\mathrm{MIC} \dagger$ & $\operatorname{MLC} \dagger$ & $\mathrm{MIC} \dagger$ & $\operatorname{MLC} \dagger$ \\
\hline \multicolumn{15}{|l|}{ Yeast strains } \\
\hline Candida albicans ATCC 10231 & $0 \cdot 64$ & $0 \cdot 64$ & $0 \cdot 16$ & $0 \cdot 32$ & $0 \cdot 16$ & $0 \cdot 16-0 \cdot 32$ & $5-10$ & $>10$ & $2 \cdot 5-5$ & $5-10$ & 1 & $>128$ & NT & NT \\
\hline C. albicans $\mathrm{H} 37$ & $0 \cdot 32$ & $0 \cdot 32-0 \cdot 64$ & $0 \cdot 16$ & $0 \cdot 32$ & $0 \cdot 16$ & $0 \cdot 16-0 \cdot 32$ & 5 & $>10$ & 5 & $5-10$ & 64 & $>128$ & NT & NT \\
\hline C. albicans M1 & $0 \cdot 32-0 \cdot 64$ & $0 \cdot 64$ & $0 \cdot 16$ & $0 \cdot 32$ & $0 \cdot 16$ & $0 \cdot 32$ & $5-10$ & $>10$ & $2 \cdot 5-5$ & $5-10$ & 2 & 128 & NT & NT \\
\hline C. tropicalis ATCC 13803 & $0 \cdot 32-0 \cdot 64$ & $0 \cdot 32-0 \cdot 64$ & $0 \cdot 16-0 \cdot 32$ & $0 \cdot 32$ & $0 \cdot 16$ & $0 \cdot 16-0 \cdot 32$ & $5-10$ & $>10$ & $10-20$ & $\geqslant 20$ & 4 & $>128$ & NT & NT \\
\hline C. tropicalis $\mathrm{H} 18$ & $0 \cdot 64$ & $0 \cdot 64$ & $0 \cdot 16-0 \cdot 32$ & $0 \cdot 32$ & $0 \cdot 16$ & $0 \cdot 16-0 \cdot 32$ & $5-10$ & $>10$ & $10-20$ & $10-20$ & 2 & $>128$ & NT & NT \\
\hline C. glabrata $\mathrm{H} 16$ & $0 \cdot 32-0 \cdot 64$ & $0 \cdot 32-0 \cdot 64$ & $0 \cdot 16$ & $0 \cdot 32$ & $0 \cdot 16$ & $0 \cdot 32$ & $5-10$ & $>10$ & 5 & 10 & 16 & 16 & NT & NT \\
\hline C. glabrata $\mathrm{H} 30$ & $0 \cdot 64$ & $0 \cdot 64$ & $0 \cdot 32$ & $0 \cdot 32$ & $0 \cdot 16$ & $0 \cdot 32$ & 10 & $>20$ & $5-10$ & 20 & 32 & 32 & NT & NT \\
\hline C. krusei ATCC 6258 & $0 \cdot 32-0 \cdot 64$ & $0 \cdot 32-0 \cdot 64$ & $0 \cdot 16-0 \cdot 32$ & $0 \cdot 32$ & $0 \cdot 16$ & $0 \cdot 16-0 \cdot 32$ & $5-10$ & 10 & $5-10$ & 10 & 64 & $64-128$ & NT & NT \\
\hline C. krusei $\mathrm{H} 9$ & $0 \cdot 32-0 \cdot 64$ & $0 \cdot 32-0 \cdot 64$ & $0 \cdot 16-0 \cdot 32$ & $0 \cdot 32$ & $0 \cdot 16$ & $0 \cdot 16-0 \cdot 32$ & $5-10$ & 10 & $5-10$ & 10 & 64 & $64-128$ & NT & NT \\
\hline C. guilliermondii MAT23 & $0 \cdot 32$ & $0 \cdot 32$ & $0 \cdot 16$ & $0 \cdot 16$ & $0 \cdot 08-0 \cdot 16$ & $0 \cdot 16$ & 5 & 10 & $1 \cdot 25-2 \cdot 5$ & $2 \cdot 5-5$ & 8 & 8 & NT & NT \\
\hline C. parapsilosis ATCC 90018 & $0 \cdot 64$ & $0 \cdot 64$ & $0 \cdot 32$ & $0 \cdot 32$ & $0 \cdot 16$ & $0 \cdot 16-0 \cdot 32$ & $2 \cdot 5$ & $>20$ & 5 & 20 & $<1$ & $<1$ & NT & NT \\
\hline \multicolumn{15}{|c|}{ Filamentous fungi, dermatophytes } \\
\hline E. floccosum FF9 & $0 \cdot 16$ & $0 \cdot 16$ & $0 \cdot 16$ & $0 \cdot 16$ & $0 \cdot 08$ & $0 \cdot 08$ & 5 & 5 & $2 \cdot 5$ & $2 \cdot 5$ & 16 & 16 & NT & NT \\
\hline T. rubrum FF5 & $0 \cdot 32$ & $0 \cdot 32$ & $0 \cdot 16$ & $0 \cdot 16$ & $0 \cdot 08$ & $0 \cdot 08$ & $1 \cdot 25$ & $1 \cdot 25-2 \cdot 5$ & 5 & 5 & $16-32$ & 32 & NT & NT \\
\hline T. mentagrophytes FF7 & $0 \cdot 16$ & $0 \cdot 32$ & $0 \cdot 16$ & $0 \cdot 16-0 \cdot 32$ & $0 \cdot 04$ & $0 \cdot 08$ & 5 & $>5$ & 10 & 10 & $16-32$ & $32-64$ & NT & NT \\
\hline M. canis FF1 & $0 \cdot 16$ & $0 \cdot 16-0 \cdot 32$ & $0 \cdot 08$ & $0 \cdot 16$ & $0 \cdot 04$ & $0 \cdot 08$ & $2 \cdot 5$ & $2 \cdot 5$ & 5 & 5 & 128 & 128 & NT & NT \\
\hline M. gypseum FF3 & $0 \cdot 16$ & $0 \cdot 32$ & $0 \cdot 16$ & $0 \cdot 32$ & $0 \cdot 04$ & $0 \cdot 08-0 \cdot 16$ & 10 & $>10$ & 10 & 10 & $\geqslant 128$ & $\geqslant 128$ & NT & NT \\
\hline \multicolumn{15}{|l|}{ Filamentous fungi, Aspergillus } \\
\hline Aspergillus niger ATCC 16404 & $0 \cdot 32$ & $0 \cdot 64$ & $0 \cdot 16$ & $0 \cdot 64$ & $0 \cdot 16$ & $0 \cdot 16-0 \cdot 32$ & $>20$ & $>20$ & $>20$ & $>20$ & NT & NT & $1-2$ & 4 \\
\hline A. niger CECT 2574 & $0 \cdot 32$ & $0 \cdot 64$ & $0 \cdot 16$ & $0 \cdot 64$ & $0 \cdot 16$ & $0 \cdot 16-0 \cdot 32$ & $>20$ & $>20$ & 20 & $>20$ & NT & NT & 2 & 4 \\
\hline A. niger $\mathrm{F} 01$ & $0 \cdot 32$ & $0 \cdot 64$ & $0 \cdot 16$ & $0 \cdot 64$ & $0 \cdot 16$ & $0 \cdot 32$ & $>20$ & $>20$ & $>20$ & $>20$ & NT & NT & 1 & 2 \\
\hline A. fumigatus ATCC 46645 & $0 \cdot 16$ & $0 \cdot 64$ & $0 \cdot 16$ & $0 \cdot 64$ & $0 \cdot 16$ & $0 \cdot 32$ & $>20$ & $>20$ & 20 & $>20$ & NT & NT & 2 & 4 \\
\hline A. fumigatus CECT 2071 & $0 \cdot 16$ & $0 \cdot 64$ & $0 \cdot 16$ & $0 \cdot 64$ & $0 \cdot 16$ & $0 \cdot 32$ & $>20$ & $>20$ & 20 & 20 & NT & NT & $1-2$ & 4 \\
\hline A. fumigatus F05 & $0 \cdot 16$ & $0 \cdot 64$ & $0 \cdot 16$ & $0 \cdot 64$ & $0 \cdot 16$ & $0 \cdot 32$ & $>20$ & $>20$ & $10-20$ & $>20$ & NT & NT & $2-4$ & $4-8$ \\
\hline A. fumigatus $\mathrm{F} 07$ & $0 \cdot 16$ & $0 \cdot 32$ & $0 \cdot 16$ & $0 \cdot 64$ & $0 \cdot 16$ & $0 \cdot 16$ & $>20$ & $>20$ & 20 & $>20$ & NT & NT & $2-4$ & 4 \\
\hline A. fumigatus $\mathrm{F} 17$ & $0 \cdot 16$ & $0 \cdot 64$ & $0 \cdot 16$ & $0 \cdot 64$ & $0 \cdot 16$ & $0 \cdot 32$ & $>20$ & $>20$ & 20 & $>20$ & NT & NT & 2 & $4-8$ \\
\hline A. flavus F44 & $0 \cdot 32$ & $0 \cdot 64$ & $0 \cdot 32$ & $0 \cdot 64$ & $0 \cdot 32$ & $0 \cdot 32$ & $>20$ & $>20$ & 20 & 20 & NT & NT & 2 & 8 \\
\hline
\end{tabular}

${ }^{\star} \mathrm{MIC}$ and MLC were determined by a macrodilution method and expressed in $\mu \mathrm{ml}^{-1}(\mathrm{v} / \mathrm{v})$.

$\dagger \mathrm{MIC}$ and MLC were determined by a macrodilution method and expressed in $\mu \mathrm{g} \mathrm{ml}{ }^{-1}(\mathrm{w} / \mathrm{v})$. 

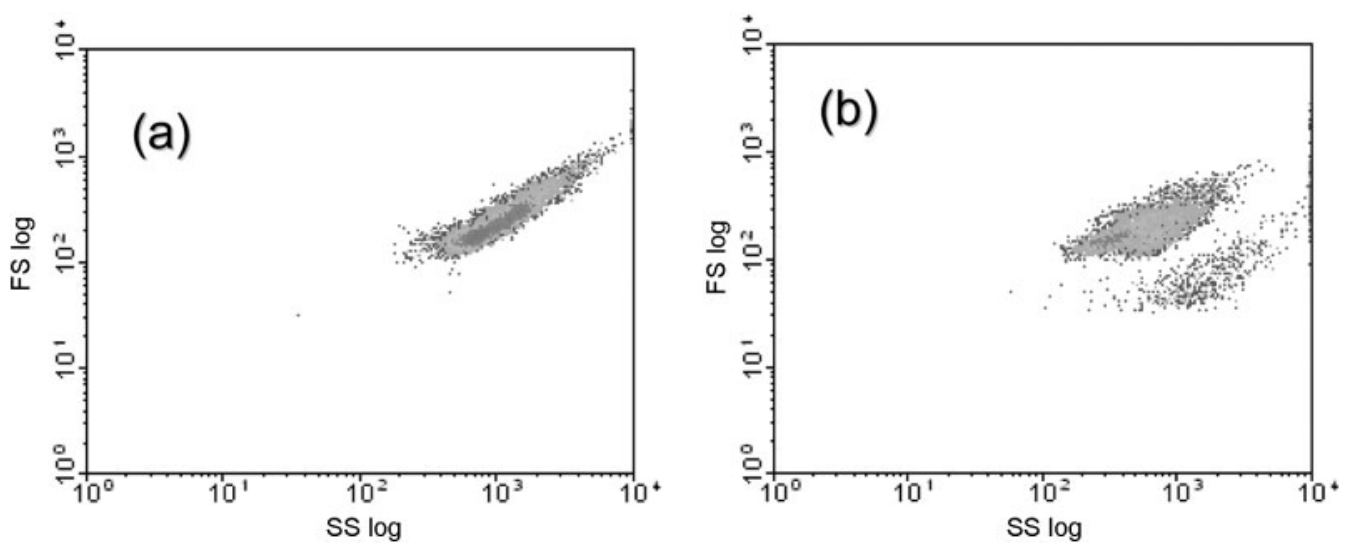

Fig. 1. Scattergram showing cell complexity (side scatter, SS log) versus cell size (forward scatter, FS log). (a) Viable cells of C. albicans; (b) cells treated with the essential oil of $T$. pulegioides at MLC value $\left(0.64 \mu \mathrm{ml}^{-1}\right)$, showing significant morphological alterations.

ranged from $0 \cdot 16$ to $0 \cdot 32 \mu \mathrm{l} \mathrm{ml}^{-1}$ against dermatophyte and Aspergillus strains. Candida showed the highest MIC values, ranging from 0.32 to $0.64 \mu \mathrm{l} \mathrm{ml}^{-1}$. For Candida and most dermatophyte strains, MIC and MLC values were similar, ranging from $0 \cdot 16$ to $0 \cdot 64 \mu \mathrm{ml}^{-1}$ (Table 2). It is difficult to attribute the activity of a complex mixture to particular constituents. Nevertheless, it is reasonable to speculate that the activity of this oil can be related to the presence of carvacrol and thymol. These compounds were found to be the most active constituents (Table 2) of T. pulegioides oil, with MIC values ranging from 0.04 to $0.32 \mu \mathrm{l} \mathrm{ml}^{-1}$ and 0.08 to $0.32 \mu \mathrm{l} \mathrm{ml}^{-1}$, respectively. The importance of the phenolic hydroxyl groups for the antimicrobial activity of the monoterpenoids has previously been reported (Adam et al., 1998; Aligiannis et al., 2001; Dorman \& Deans, 2000; Nostro et al., 2004; Sivropoulou et al., 1996). Other species of the genus Thymus, such us T. zygis and T. vulgaris, with high amounts of phenols, also show a broad spectrum of activity against a variety of pathogenic yeasts and filamentous fungi, including fungi with decreased susceptibility to fluconazole (Dorman \& Deans, 2000; Nguefack et al., 2004; Pina-Vaz et al., 2004). Nevertheless, carvacrol proved to be more active against dermatophyte strains, in a similar manner to the essential oil. MIC and MLC values were very similar and the fungistatic and fungicidal properties of the oil were suspected to be associated with high carvacrol and thymol content.

Flow cytometry was used to evaluate the effect of the essential oil on the integrity of fungal cells, using PI as fluorescent marker. The results showed that the oil acts by primary lesion of the membrane. The effect on Candida was fungicidal, with severe lesion of the membrane, as PI could penetrate most of the yeast cells (more than 95\%) after $5 \mathrm{~min}$ at the MLC value $\left(0.64 \mu \mathrm{l} \mathrm{ml}^{-1}\right)$. This effect was dose dependent, so that there were >95\% PI-positive cells at a sub-MLC concentration $\left(0 \cdot 32 \mu \mathrm{ml}^{-1}\right)$. Substantial morphological changes were observed on a scattergram of $C$. albicans cells after $1 \mathrm{~h}$ incubation at MLC values (Fig. 1). Previous work carried out with essential oils has revealed anti-Candida activity (Pina-Vaz et al., 2004; Salgueiro et al., 2003, 2004). Incubating Aspergillus with essential oil of $T$. pulegioides, PI began to stain the cells after $7 \mathrm{~h}$ incubation. At MLC values, $\sim 40 \%$ of A. fumigatus cells and $\sim 20 \%$ of $A$. niger cells were stained, the effect being dose dependent (Fig. 2). Thymol and carvacrol gave identical cytometric results to $T$. pulegioides essential oil against Candida and Aspergillus. To understand the mechanism of action on moulds, Aspergillus species were studied as typical. Aspergillus begins its germination at $\sim 7 \mathrm{~h}$ incubation, so it is understandable that it was only after this period that the essential oil was effective and PI could enter the cells. This effect is superior to the effect of most antifungals, as most of them are fungistatic.

Ergosterol is the major sterol component of the yeast cell membrane, and is responsible for maintaining cell function and integrity (Rodriguez et al., 1985). The primary

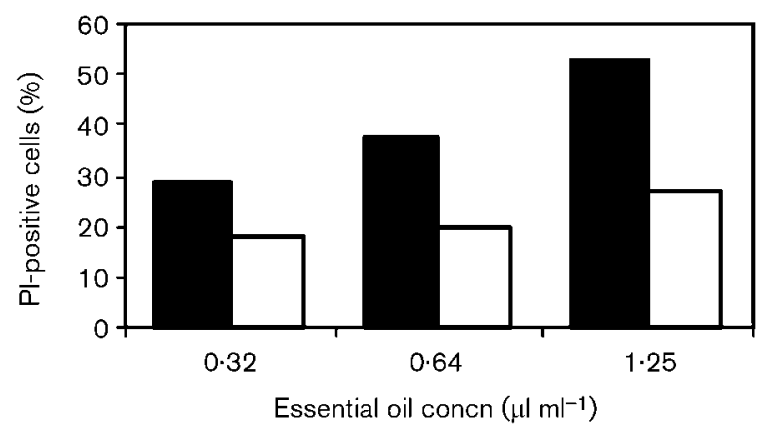

Fig. 2. Number of Pl-positive cells (dead cells) of $A$. fumigatus ATCC 46645 (black bars) and A. niger ATCC 16404 (white bars) at serial concentrations of the essential oil of T. pulegioides. 
mechanism of action by which azole antifungal drugs inhibit yeast cell growth is disruption of normal sterol biosynthetic pathways, leading to a reduction in ergosterol biosynthesis (Kelly et al., 1995). After incubation of C. albicans ATCC 10231 at MIC $\left(0.64 \mu \mathrm{ml}^{-1}\right)$ and subinhibitory $\left(0.32 \mu \mathrm{l} \mathrm{ml}^{-1}\right)$ concentrations of essential oil, a reduction of $80-100 \%$ of ergosterol content was observed. A similar effect was obtained with fluconazole at $1 \mu \mathrm{g} \mathrm{ml}^{-1}$. For $T$. rubrum, a subinhibitory essential oil concentration $\left(0.08 \mu \mathrm{l} \mathrm{ml}^{-1}\right)$ reduced ergosterol content by around $70 \%$. The essential oil of T. pulegioides therefore induces considerable impairment of the biosynthesis of ergosterol by C. albicans and T. rubrum.

The large spectrum of activity of this essential oil acting on Candida, Aspergillus and dermatophytes agrees with the mechanism of action proposed: cytoplasmic membrane lesion.

In conclusion, the findings of the present study indicate that T. pulegioides essential oil has potential as a topical antifungal agent against fungi that are pathogenic to humans. This essential oil is a broad-spectrum agent that inhibites not only dermatophytes, Aspergillus and Candida species (such as C. albicans, C. tropicalis, C. parapsilosis, $C$. guilliermondii), but also fluconazole-resistant C. albicans isolates, and C. krusei and C. glabrata, which are intrinsically resistant to fluconazole or whose resistance is easily inducible.

Given the results described above, particularly the possible mechanisms of action, which might induce side-effects in humans, these antifungals require further investigation.

The results presented should stimulate studies on toxicity, improved formulations and the determination of optimal concentrations for clinical applications, as well as comparative studies alongside currently used drugs of the therapeutic efficacy of essential oils to control mucocutaneous infections.

\section{ACKNOWLEDGEMENTS}

This work was supported by Fundação para a Ciência e Tecnologia (FCT) and Fundo Europeu de Desenvolvimento Regional (FEDER) (Programa Operacional Ciência, Tecnologia, Inovação-POCTI/40167/ 2001).

\section{REFERENCES}

Adam, K., Sivropoulou, A., Kokkini, S., Lanaras, T. \& Arsenakis, M. (1998). Antifungal activities of Origanum vulgare subsp. hirtum, Mentha spicata, Lavandula angustifolia, and Salvia fruticosa essential oils against human pathogenic fungi. J Agric Food Chem 46, 1739-1745.

Adams, R. P. (1995). Identification of Essential Oil Components by Gas Chromatography/Mass Spectroscopy. Carol Stream, IL: Allured Publishing Corporation.
Aligiannis, N., Kalpoutzakis, E., Mitaku, S. \& Chinou, I. B. (2001). Composition and antimicrobial activity of the essential oils of two Origanum species. J Agric Food Chem 38, 4168-4170.

Arthington-Skaggs, B. A., Jradi, H., Desai, T. \& Morrison, C. J. (1999). Quantification of ergosterol content: novel method for determination of fluconazole susceptibility of Candida albicans. J Clin Microbiol 37, 3332-3337.

Bruneton, J. (1999). Partie 3, Terpènes et steroids, huiles essentielles. In Pharmacognosie. Paris: Éditions Tec\&Doc \& Éditions Médicales Internationals.

Council of Europe (1997). Methods of Pharmacognosy. In European Pharmacopoeia, 3rd edn, pp. 121-122. Strasbourg: European Department for the Quality of Medicines.

Dorman, H. J. \& Deans, S. G. (2000). Antimicrobial agents from plants: antibacterial activity of plant volatile oils. J Appl Microbiol 88, 308-316.

Eggimann, P., Garbino, J. \& Pittet, D. (2003). Management of Candida species infections in critically ill patients. Lancet Infect Dis $\mathbf{3}$, 772-785

Joulain, D. \& Konig, W. A. (1998). The Atlas of Spectral Data of Sesquiterpene Hydrocarbons. Hamburg: E. B.-Verlag.

Kalemba, D. \& Kunicka, A. (2003). Antibacterial and antifungal properties of essential oils. Curr Med Chem 10, 813-829.

Kelly, S. L., Lamb, D. C., Corran, A. J., Baldwin, B. C. \& Kelly, D. E. (1995). Mode of action and resistance to azole antifungals associated with the formation of 14 alpha-methylergosta-8,24(28)-dien-3 beta, 6 alpha-diol. Biochem Biophys Res Commun 207, 910-915.

McNeil, M. M., Nash, S. L., Hajjeh, R. A., Phelan, M. A., Conn, L. A., Plikaytis, B. P. \& Warnock, D. W. (2001). Trends in mortality due to invasive mycotic diseases in the United States, 1980-1997. Clin Infect Dis 33, 641-647.

National Committee for Clinical Laboratory Standards (1997). Reference Method for Broth Dilution Antifungal Susceptibility Testing of Yeasts: approved standard. Document M27-A. Wayne, PA: National Committee for Clinical Laboratory Standards.

National Committee for Clinical Laboratory Standards (2002). Reference Method for Broth Dilution Antifungal Susceptibility Testing of Filamentous Fungi: approved standard. Document M38-A. Wayne, PA: National Committee for Clinical Laboratory Standards.

Nguefack, J., Leth, V., Amvam Zollo, P. H. \& Mathur, S. B. (2004). Evaluation of five essential oils from aromatic plants of Cameroon for controlling food spoilage and mycotoxin producing fungi. Int J Food Microbiol 94, 329-334.

Nostro, A., Blanco, A. R., Cannatelli, M. A., Enea, V., Flamini, G., Morelli, I., Roccaro, A. S. \& Alonzo, V. (2004). Susceptibility of methicillin-resistant staphylococci to oregano essential oil, carvacrol and thymol. FEMS Microbiol Lett 230, 191-195.

Pina-Vaz, C., Sansonetty, F., Rodrigues, A., Costa-de-Oliveira, S., Martinez-de-Oliveira, J. \& Fonseca, A. F. (2001). Cytometric approach for rapid evaluation of susceptibility of Candida strains to antifungals. Clin Microbiol Infect 7, 609-618.

Pina-Vaz, C., Rodrigues, A. G., Pinto, E., Costa-de-Oliveira, S., Tavares, C., Salgueiro, L. R., Cavaleiro, C., Gonçalves, M. J. \& Martinez-de-Oliveira, J. (2004). Antifungal activity of Thymus oils and their major compounds. J Eur Acad Dermatol 18, 73-78.

Rapp, R. P. (2004). Changing strategies for the management of invasive fungal infections. Pharmacotherapy 24, 4S-28S.

Rodriguez, R. J., Low, C., Bottema, C. D. \& Parks, L. W. (1985). Multiple functions for sterols in Saccharomyces cerevisiae. Biochim Biophys Acta 837, 336-343.

Salgueiro, L. R. (1994). Os tomilhos portugueses e os seus óleos essenciais. PhD thesis, University of Coimbra, Portugal. 
Salgueiro, L. R., Cavaleiro, C., Pinto, E. \& 7 other authors (2003). Chemical composition and antifungal activity of the essential oil of Origanum virens on Candida species. Planta Med 69, 871-874.

Salgueiro, L. R., Pinto, E., Gonçalves, M. J. \& 7 other authors (2004). Chemical composition and antifungal activity of the essential oil of Thymbra capitata. Planta Med 70, 572-575.
Sivropoulou, A., Papanikolaou, E., Nikolaou, C., Kokkini, S., Lanaras, T. \& Arsenakis, M. (1996). Antimicrobial and cytotoxic activities of Origanum essential oils. J Agric Food Chem 44, 12021205.

Stahl-Biskup, E. \& Sáez, F. (2002). Thyme - the Genus Thymus. London: Taylor \& Francis. 